\title{
ORAL MISOPROSTOL VERSUS INTRAMUSCULAR OXYTOCIN IN THE ACTIVE MANAGEMENT OF THE THIRD STAGE OF LABOUR
}

\author{
By
Wael Abd Elaty Abd Allah, Farid Ibrahem Hassan and Mofeed Fawzy Mohamed

Department of Obstetrics and Gynecology, Al-Azhar Faculty of Medicine, Cairo, Egypt

E-mail: wael2a4@yahoo.com

\begin{abstract}
Background: The third stage of labor is defined as the time between the delivery of the baby and delivery of the placenta. The third stage of labor is potentially the most dangerous part for the mother. The main risk is the occurrence of postpartum hemorrhage.

Objective: To compare the efficacy and safety of oral misoprostol with intramuscular oxytocin in the active management of third stage of labor for the prevention of postpartum hemorrhage.

Patient and Methods: The study was conducted in the labor ward of Obstetrics and Gynecology Department at Imbaba General Hospital from September 2018 till September 2019. This study included four hundred healthy pregnant women during the course of normal labor. Patients in this study were randomly divided into two equal groups: Group (I) received 600 mcg Misoprostol orally within 1 minute of delivery of the baby and Group (II) received 10 IU oxytocin intramuscularly within 1 minute of delivery of the baby. We compared the two groups using computer programs to evaluate the safety and efficacy of each drug. The primary outcome measure was postpartum fall in haemoglobin after $8 \mathrm{~h}$ of delivery. Secondary outcome measure was duration of third stage of labor, need for an additional uterotonic drug, need for blood transfusion and side effects of both the drugs.

Results: There was no significant difference between the two groups regarding the duration of the third stage of labor, the change in hemoglobin and hematocrit levels from before labor to 8 hours postpartum, and the occurrence of complications (the need for more utrotonic drugs and the need for blood transfusion). As regard the duration of third stage of labor, there was a slight advantage for the oxytocin group over the misoprostol group, $4 \%$ of cases in oxytocin group have side effects, while $13 \%$ of cases in misoprostol group have sides effects in the form of nausea, vomiting, fever, shivering.
\end{abstract}

Conclusions: No major difference in oral misoprostol and intramuscular oxytocin in the management of third stage of labor.

Keywords: Intramuscular oxytocin, oral misoprostol, third stage of labor.

\section{INTRODUCTION}

Postpartum hemorrhage (PPH) is an important cause of maternal morbidity and mortality after delivery especially in lowincome countries (Say et al., 2014). PPH is often associated with the failure of the uterus to contract after delivery and categorized as blood loss of $500 \mathrm{~mL}$ or more following vaginal delivery or 1,000 $\mathrm{mL}$ after cesarean delivery (Evensen et al., 2017). Reduction in maternal mortality is part of the sustainable development goals set by the United Nations. One strategy for achieving this is to ensure that the 
most effective evidence-based therapies are used to manage $\mathrm{PPH}$, and that global standards follow evidence-based guidelines (Adler et al., 2012).

Currently, the World Health Organization (WHO) recommends active management of the third stage of labor (AMTSL) to prevent PPH. AMTSL, as a prophylactic intervention, is composed of a package of three components or steps: 1) administration of a uterotonic, immediately after birth of the baby; 2) controlled cord traction (CCT) to deliver the placenta; and 3) massage of the uterine fundus after the placenta is delivered. The administration of an uterotonic to the mother immediately after the birth of the baby is identified as the most important step (Begley et al., 2019).

Physiologically,

myometrial contractions are the main determinant of placental separation and hemostasis (physiological sutures or living ligatures). Prophylactic use of uterotonics is standard of care world-wide (Lier et al., 2018).

Oxytocin is a 9-amino-acid peptide that is secreted in vivo by the posterior pituitary gland; primarily it promotes smooth muscle contraction. Its postpartum release stimulates both uterine contractions for stopping blood loss, and the breast-milk reflex. The dose used for $\mathrm{PPH}-$ prophylaxis varies widely, ranging from 2 IU to 10 IU (international units) for both intravenous bolus and intramuscular injections (Westhoff et al., 2013). The routine use of oxytocin has been shown to reduce the incidence of postpartum hemorrhage (Salati et al., 2019). Although oxytocin is the gold standard drug for prevention and treatment of $\mathrm{PPH}$, it requires cool storage, sterile equipment, and trained personnel, so that routine use of oxytocin in lowresource settings may be difficult (Prata et al., 2013).

Prostaglandins are from the drugs used for management of postpartum hemorrhage (Smith et al., 2013). Misoprostol is a synthetic analogue of prostaglandin $\mathrm{E} 1$ and an effective uterotonic factor which can be used for treatment of uterine atony. Its advantages in obstetrics and gynecology are known and its usage especially for management of postpartum hemorrhage is increasing (Prata et al., 2013). The role of misoprostol, a prostaglandin E1 analog, in the prevention and treatment of $\mathrm{PPH}$ has evolved over time due to its long shelf life and multiple routes of administration, which make it more suitable for lowresource settings with limited skilled providers. Misoprostol is administered orally, and hence does not require special training for its administration. It does not need special storage facilities (does not require refrigeration) and is heat stable, especially in hot tropical environments (Weeks, 2015).

The present study aimed at comparing the efficacy and safety of oral misoprostol with intramuscular oxytocin in the active management of third stage of labor.

\section{PATIENTS AND METHODS}

This study was conducted in the labor ward of Obstetrics and Gynecology Department at Imbaba General Hospital from September 2018 till September 2019. The study included four hundred healthy pregnant women in Imbaba General 
Hospital during the course of normal labor.

The study was approved by Department of Obstetrics and Gynaecology at Al-Azhar University in Egypt. Full informed verbal consents were obtained from all patients involved in the study and details of the procedure were explained to them. Confidentiality and personal privacy were respected in all levels of the study. Collected data were not be used for any other purpose.

\section{Inclusion criteria:}

Pregnant women aged 20-35 years, low parity $<5$, spontaneous onset of labor at term (37 completed weeks to 42 completed weeks), and having single living baby in cephalic presentation

\section{Exclusion Criteria:}

Women with induced labor, instrumental delivery, or cesarean delivery, women with scarred uterus, multiple pregnancy, polyhydramnios (amniotic fluid index >20), malpresentations (breech, face). With medical disorders like severe anemia (haemoglobin $<7 \quad \mathrm{~g} / \mathrm{dl}$ ), gestational hypertension, pre-eclampsia, diabetes mellitus were excluded from the study.

\section{Patients were randomly divided into two equal groups:}

Group (I) received $600 \mathrm{mcg}$ Misoprostol orally within 1 minute of delivery of the baby.

Group (II) received 10 IU Oxytocin intramuscularly within 1 minute of delivery of the baby.

Hemoglobin $(\mathrm{Hb})$ and hematocrit (Hct) levels were measured before the delivery. The third stage of labor was managed by clamping and cutting the cord, delivery of placenta by controlled cord traction, and uterine massage. All placentae were examined to rule out retained bits of placenta and membranes.

If the placenta was not delivered within 30 minutes of the delivery of the baby, a diagnosis of retained placenta was made, and it was removed manually. The duration of third stage was noted and recorded.

Uterine massage was done for about 10-15 minutes after expulsion of placenta until the uterus became well contracted in all the women, and then the women were taught to massage their uterus every 30 minutes for 2 hours after delivery. Episiotomy wound, tears and lacerations if present were immediately repaired.

Maternal pulse and blood pressure were recorded immediately after delivery. Once the hemostasis was ensured and the uterus sufficiently contracted, the women were shifted from the labor room and monitored in the post labor room for one hour after delivery. Women with delayed hemorrhage, which needed additional uterotonics, exploration and or blood transfusion, were recorded. Hemoglobin $(\mathrm{Hb})$ and hematocrit (Hct) levels were measured $8 \mathrm{~h}$ postpartum. The women were asked for side effects like vomiting, abdominal pain, diarrhea, shivering, fever or other complications during the postnatal period.

Primary Outcome measures: Postpartum fall in hemoglobin after $8 \mathrm{~h}$ of delivery.

Secondary outcome measures: Duration of third stage of labor, need for an additional uterotonic drug, need for blood 
transfusion, and side effects of both the drugs.

\section{Statistical Analysis:}

Data were collected, revised, coded and entered to the Statistical Package for the social science (IBM SPSS) version 23. The quantitative data were presented as mean, standard deviations and ranges when parametric. Also qualitative variables were presented as number and percentages. The comparison between groups regarding qualitative data was done by using Chi-square test. The comparison between two independent groups with quantitative data and parametric distribution was done by using Mann- whitney $u$ test. The mean difference was calculated by the following equation (Post - Pre) in hemoglobin and hematocrit.

The confidence interval was set to $95 \%$ and the margin of error accepted was set to $5 \%$. So, the p-value was considered significant when $\mathrm{p}$-value $\leq 0.05$.

\section{RESULTS}

This prospective study evaluated 400 women (200 parturients each in the two study groups). There was no statistically significant difference among the two groups as regarding the three demographic variables of the parturients their mean age, parity, period of gestation in weeks, the amount of decrease in hemoglobin level and hematocrit level from before to after labor and duration of third stage of labor. The mean duration of the third stage of labor was 3.35 minutes in the oxytocin group and 3.48 minutes in the misoprostol group (Table 1).

Table (1): Comparison between oxytocin group and misoprostol group regarding the three demographic variables of the parturients (their mean age, parity and period of gestation in weeks), duration of the 3rd stage of labor and the mean difference of hemoglobin level and hematocrit level from before to after labor

\begin{tabular}{|c|c|c|c|c|}
\hline \multirow{2}{*}{\multicolumn{2}{|c|}{\begin{tabular}{|ll} 
Parameters & Groups \\
\end{tabular}}} & Oxytocin group & Misoprostol group & \multirow{2}{*}{ P-value } \\
\hline & & No. $=200$ & No. $=200$ & \\
\hline \multirow{2}{*}{$\begin{array}{l}\text { Age } \\
\text { (yrs) }\end{array}$} & Mean \pm SD & $26.22 \pm 3.68$ & $26.20 \pm 3.41$ & \multirow{2}{*}{0.955} \\
\hline & Range & $20-34$ & $20-34$ & \\
\hline \multirow{5}{*}{$\begin{array}{l}\text { Parity } \\
\text { (no) }\end{array}$} & 0 & $28(14.0 \%)$ & $30(15.0 \%)$ & \multirow{5}{*}{0.269} \\
\hline & 1 & $50(25.0 \%)$ & $50(25.0 \%)$ & \\
\hline & 2 & $52(26.0 \%)$ & $64(32.0 \%)$ & \\
\hline & 3 & $58(29.0 \%)$ & $40(20.0 \%)$ & \\
\hline & 4 & $12(6.0 \%)$ & $16(8.0 \%)$ & \\
\hline \multirow{2}{*}{$\begin{array}{c}\text { GA } \\
(\mathrm{wks})\end{array}$} & Mean \pm SD & $38.86 \pm 0.89$ & $38.88 \pm 0.90$ & \multirow{2}{*}{0.823} \\
\hline & Range & $37-41$ & $37-41$ & \\
\hline \multicolumn{5}{|c|}{ Duration of third stage of labor } \\
\hline $\begin{array}{l}\text { Duration } \\
\text { (min) }\end{array}$ & $\begin{array}{l}\text { Mean } \pm \text { SD } \\
\text { Range }\end{array}$ & $\begin{array}{c}3.35 \pm 1.62 \\
1.5-10\end{array}$ & $\begin{array}{c}3.48 \pm 1.76 \\
2-15\end{array}$ & 0.434 \\
\hline \multicolumn{5}{|c|}{ Mean difference of hemoglobin level and hematocrit level from before to after labor } \\
\hline \multicolumn{2}{|c|}{$\mathrm{Hg}(\mathrm{g} / \mathrm{dl})$} & $0.74 \pm 0.25$ & $0.72 \pm 0.24$ & 0.415 \\
\hline \multicolumn{2}{|c|}{$\mathrm{HCT}(\%)$} & $2.54 \pm 1.1$ & $2.6 \pm 0.80$ & 0.533 \\
\hline
\end{tabular}


There was no statistically significant difference among the two groups as regarding the need for more uterotonic drugs (16 patients in the oxytocin group and 26 patients in misoprostol group who need to additional uterotonic drugs), and the need for blood transfusion. 6 patients in the oxytocin group and 8 patients in the misoprostol group who need to blood transfusion. Regarding side effects there was a statistically significant difference between the two studied groups, 8 cases have side effects in oxytocin group while 26 cases in misoprostol group have side effects (Table 2).

Table (2): Comparison between oxytocin group and misoprostol group regarding the need for more uterotonic drugs, the need for blood transfusion and side effects

\begin{tabular}{|c|c|c|c|c|}
\hline \multirow{2}{*}{\multicolumn{2}{|c|}{$\begin{array}{ll}\text { Parameters } & \text { Groups } \\
\end{array}$}} & Oxytocin group & Misoprostol group & \multirow{2}{*}{ P-value } \\
\hline & & No. $=200$ & No. $=200$ & \\
\hline \multirow{2}{*}{$\begin{array}{c}\text { Need more } \\
\text { utrotonic drugs }\end{array}$} & No & $184(92.0 \%)$ & $174(87.0 \%)$ & \multirow{2}{*}{0.103} \\
\hline & Yes & $16(8.0 \%)$ & $26(13.0 \%)$ & \\
\hline $\begin{array}{l}\text { Need blood } \\
\text { transfusion }\end{array}$ & $\begin{array}{l}\text { No } \\
\text { Yes }\end{array}$ & $\begin{array}{c}194(97.0 \%) \\
6(3.0 \%)\end{array}$ & $\begin{array}{c}192(96.0 \%) \\
8(4.0 \%)\end{array}$ & 0.586 \\
\hline \multicolumn{5}{|l|}{ Side effects } \\
\hline $\begin{array}{c}\text { NO } \\
\text { Fever } \\
\text { Shivering } \\
\text { Vomiting } \\
\text { Nausea }\end{array}$ & & $\begin{array}{l}192(96.0 \%) \\
2(1.0 \%) \\
2(1.0 \%) \\
2(1.0 \%) \\
2(1.0 \%)\end{array}$ & $\begin{array}{c}174(87.0 \%) \\
6(3.0 \%) \\
4(2.0 \%) \\
8(4.0 \%) \\
8(4.0 \%)\end{array}$ & 0.029 \\
\hline
\end{tabular}

\section{DISCUSSION}

This comparative study has shown that, there was no statistically significant difference among the 2 groups regarding age, parity, gestational age, hemoglobin and hematocrit level before labor and duration of third stage of labor. The mean duration of the third stage of labor was 3.35 minutes in oxytocin group, 3.48 minutes in the misoprostol group. There was no significant statistical difference between the two groups regarding the change in Hemoglobin and Hematocrit levels from before labor to $8 \mathrm{~h}$ postpartum. Regarding the occurrence of episiotomy or perineal tears, there was no significant difference between the two groups.

Statistical analysis between the two groups showed no significant difference in need to additional utrotonic drugs and the need for blood transfusion.

In the present study, there was a statistical significant difference in the side effects between the two groups. The oxytocin group has fewer side effects than misoprostol group. $4 \%$ of cases in oxytocin group have side effects while $13 \%$ of cases in misoprostol group have side effects in the form of nausea, vomiting, fever and shivering. These undesirable side effects of misoprostol were found to be self-limiting, fever and shivering could be managed by simply covering the patient with blankets and antipyretics.

Our study was supported by the finding in the study of Abdulkarim et al. (2015) comparing oral misoprostol $600 \mathrm{mcg}$ plus placebo injection versus intramuscular 
oxytocin $10 \mathrm{IU}$ plus oral placebo in active management of 3rd stage of labor which show that oral misoprostol is efficacious and a good alternative to oxytocin for AMTSL.

Saima et al. (2014) showed insignificant difference in average amount of blood loss and average drop in hemoglobin concentration after $24 \mathrm{~h}$ of labor between oral misoprostol $600 \mathrm{mcg}$ with intramuscular oxytocin $10 \mathrm{IU}$ in active management of $3^{\text {rd }}$ stage of labor.

Afolabi et al. (2010) reported that 400ug oral misoprostol appeared to be as effective and as safe as 10 IU intramuscular oxytocin in the active management of the third stage of labor.

Our study was supported by the finding in the study of Lata Rajoria and Anita (2018) that there was no significant statistical difference between sublingual misoprostol versus intramuscular oxytocin in active management of 3rd stage of labor regarding mean volume of blood loss.

\section{CONCLUSION}

This study was comparing IM oxytocin vs oral misoprostol in active management in third stage of labor, which failed to show any significant difference between two groups regarding duration of third stage of labor, change in Hemoglobin and Hematocrit levels from before labor to 8 hours postpartum, need for more utrotonic drugs.

As for the duration of third stage of labor, the oxytocin group showed a slightly shorter in duration than the Misoprostol group. As for side effects the oxytocin group showed fewer side effects than misoprostol group.
To date Oxytocin is the drug of choice in the management of the third stage of labor and Misoprostol is an option when oxytocin is not available.

\section{REFERENCES}

1. Abdulkarim O, Munir'dee A, Rakiya S, Abiodun P, Abiodun A, Kikelomo $T$ and Ishaq F. (2015): Double-blind randomized controlled trial comparing misoprostol and oxytocin for management of the third stage of labor in a Nigerian hospital International Journal of Obstetrics and Gynecology, 129 (3): 227-30.

2. Adler A J, Filippi V, Thomas S L and Ronsmans C (2012): Incidence of Severe Acute Maternal Morbidity Associated with Abortion: A Systemic Review. Tropical Medicine and International Health, 17 (2): 177-90.

3. Afolabi EO, Kuti O, Oiji EO and Ogunniyi SO (2010): Oral misoprostol versus intramuscular oxytocin in active management of third stage of Labour.Singapore Med J, 51(3):207-11.

4. Begley CM, Gyte GML, Devane D, McGuire W and Weeks A (2019): Active versus expectant management for women in the third stage of labour. Cochrane Database of Systematic Reviews, Issue 2. Art No.: CD007412.

5. Evensen A, Anderson JM, Fontaine $P$ (2017): Postpartum hemorrhage: prevention and treatment. American Family Physician, 95(7):442-49.

6. Lata Rajoria and Anita (2018): A randomized control study: Sublingual misoprostol versus intramuscular oxytocin in the active management of third stage of labor IJSAR International Journal of Sciences \& Applied Research, 5(2): 31-35.

7. Lier H, von Heymann C, Korte $W$ and Schlembach D (2018): Peripartum Hemorrhage. Hemostatic Aspects of the New German PPH Guideline, 45:127-135.

8. McLintock $C$ and James AH (2011): Obstetric hemorrhage. J Thromb Haemost., 9: 1441-51. 
9. Prata N, Passano P, Bell S, Rowen T and Potts M. (2013): New hope: communitybased misoprostol use to prevent postpartum hemorrhage. Health Policy Plan, 28(4):339346.

10. Saima A, Sarah K, Gulfishan $H$ and Nargis S (2014): Oral misoprostol versus oxytocin in the management of third stage of labor J Pak Med Assoc., 64(4):428-32.

11. Salati JA, Leathersich SJ, Williams MJ, Cuthbert A and Tolosa JE (2019): Prophylactic oxytocin for the third stage of labor to prevent postpartum hemorrhage. Cochrane Database of Systematic Reviews, Issue 4. Art. No.: CD001808.

12. Say L, Chou D, Gemmill A, Tuncalp O, Moller AB, Daniels J, Gulmezoglu AM, Temmerman $M$ and Alkema $L$ (2014): Global causes of maternal death: a WHO systematic analysis. Lancet Glob Health; 2(6):e323-e333.
13. Smith JM, Gubin R, Holston MM, Fullerton $J$ and Prata N (2013): Misoprostol for postpartum hemorrhage prevention at home birth: an integrative review of global implementation experience to date. BMC Pregnancy Childbirth; 13(1):11-44.

14. Weeks A. (2015): The prevention and treatment of postpartum hemorrhage: what do we know, and where do we go to next? BJOG; 122(2):202-210.

15. Westhoff G, Cotter AM and Tolosa JE (2013): Prophylactic oxytocin for the third stage of labour to prevent postpartum hemorrhage. Cochrane Database Syst Rev., 379:1721-1727. 


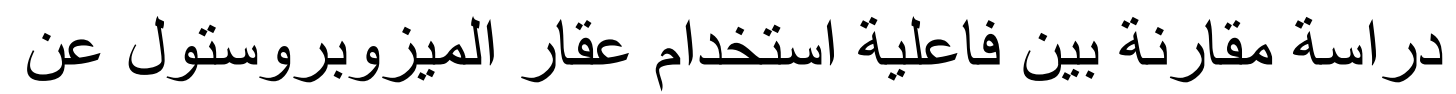

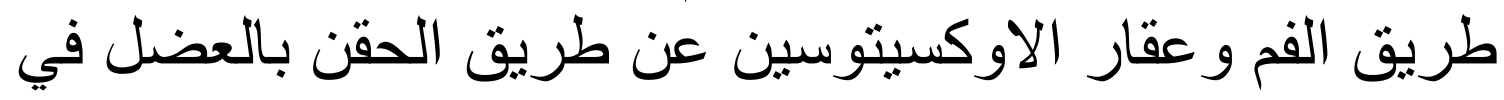

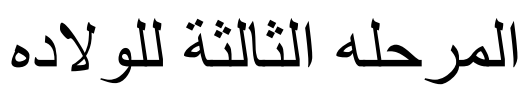

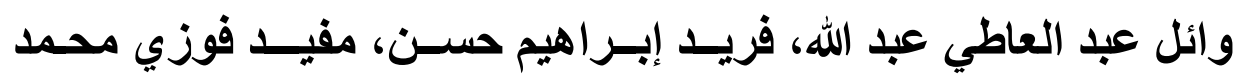

قسم النساء والتوليد، كليه الطب، جامعة الازهر

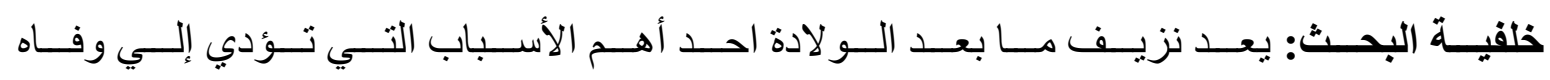

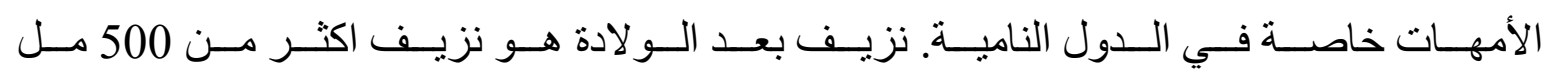

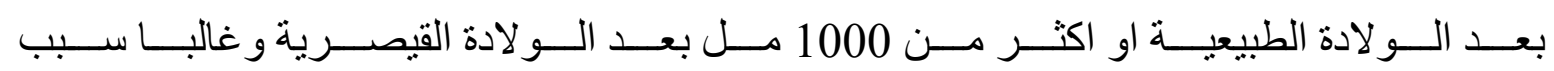

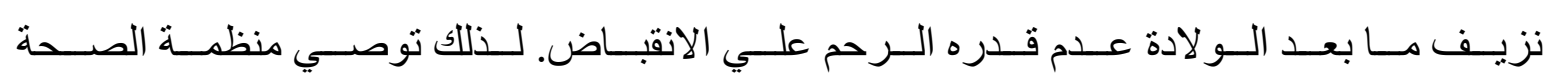

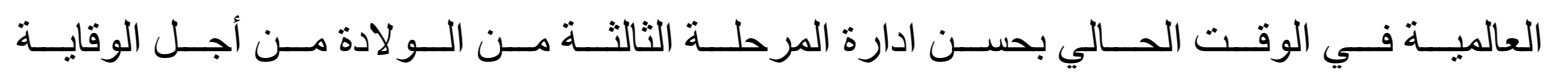
من النزيف التالي للوضع. التي تتكون من حزمة من ثلاثة مكونات أو خطوات:

1. إعطاء عقار يساعد علي انقباض الرحم، مباثرة بعد ولادة الطفل.

2. 3. تدليك الرحم بعد أن يتم نزول المشيمة.

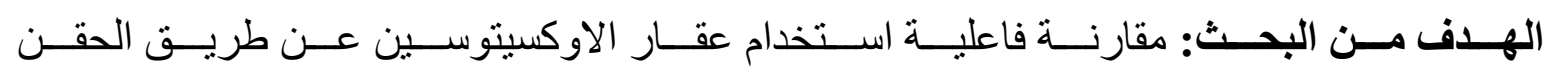

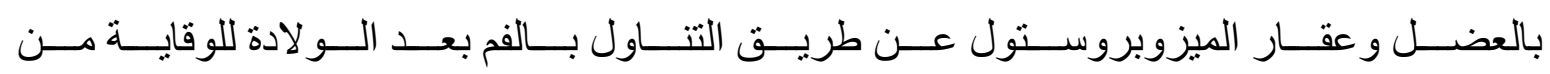
نزيف مابعد الو لادة.

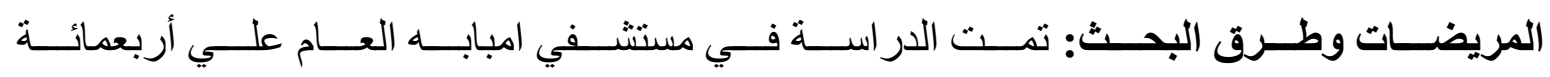

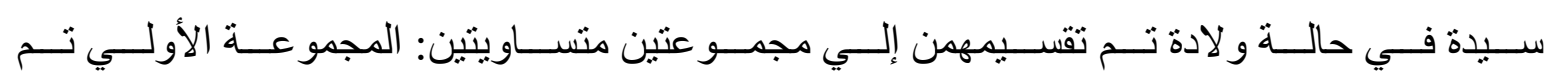

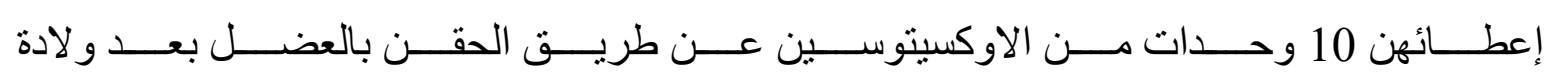

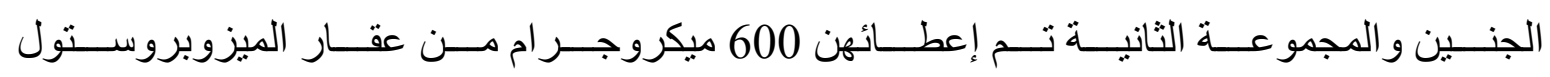
عن طريق الفم بعد و لادة الجنين.

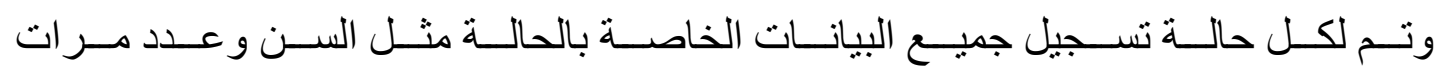

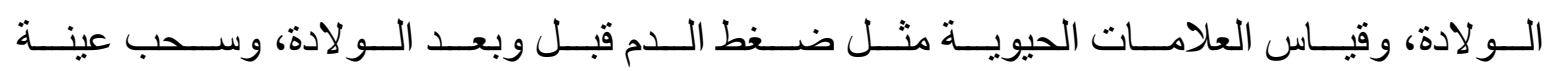




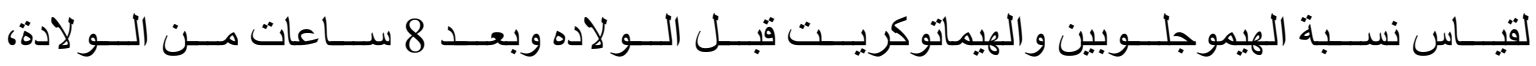

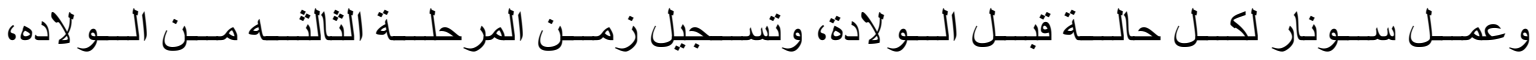

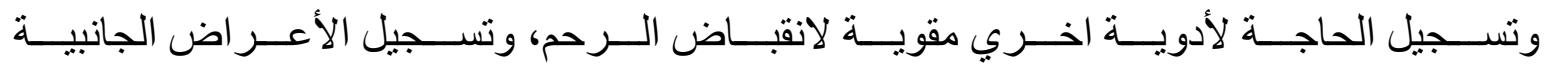
لكل حالة.

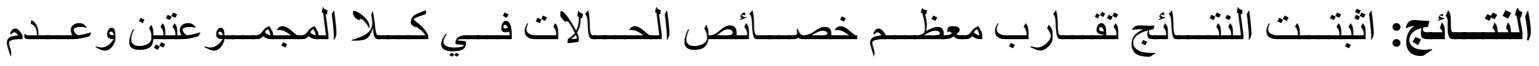

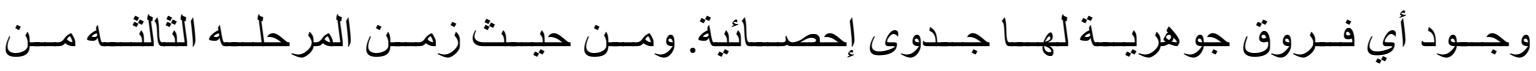

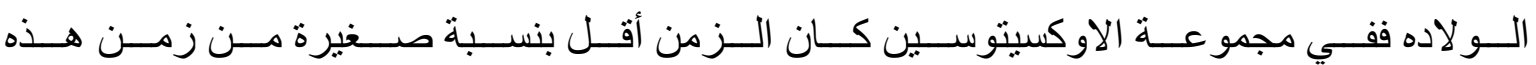

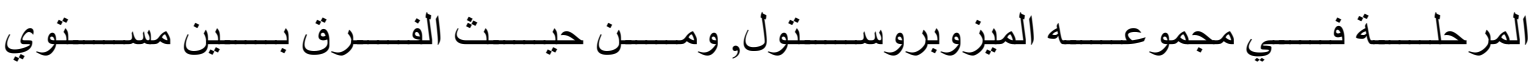

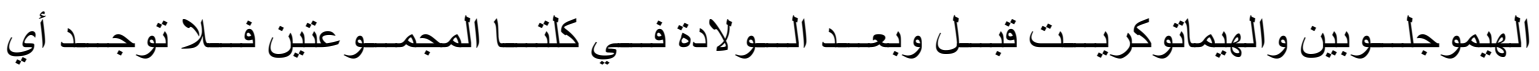
فروق جوهرية لها جدوي إحصائية.

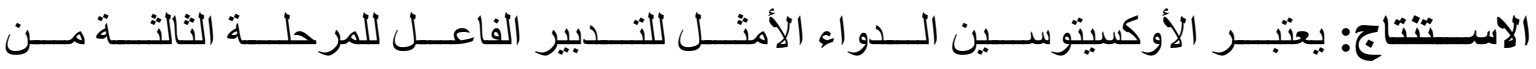

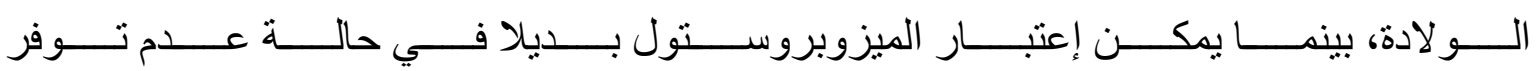
الأوكسيتوسين. 